[JULIANA SCHMITT]

Pós-doutoranda em Artes, Cultura e Linguagens na Universidade Federal de Juiz de Fora (UFJF)

E-mail:juschmittju@gmail.com

\title{
¡Rómpelo-tu-mismo! Histórias do punk argentino e outras rebeldias portenhas
}




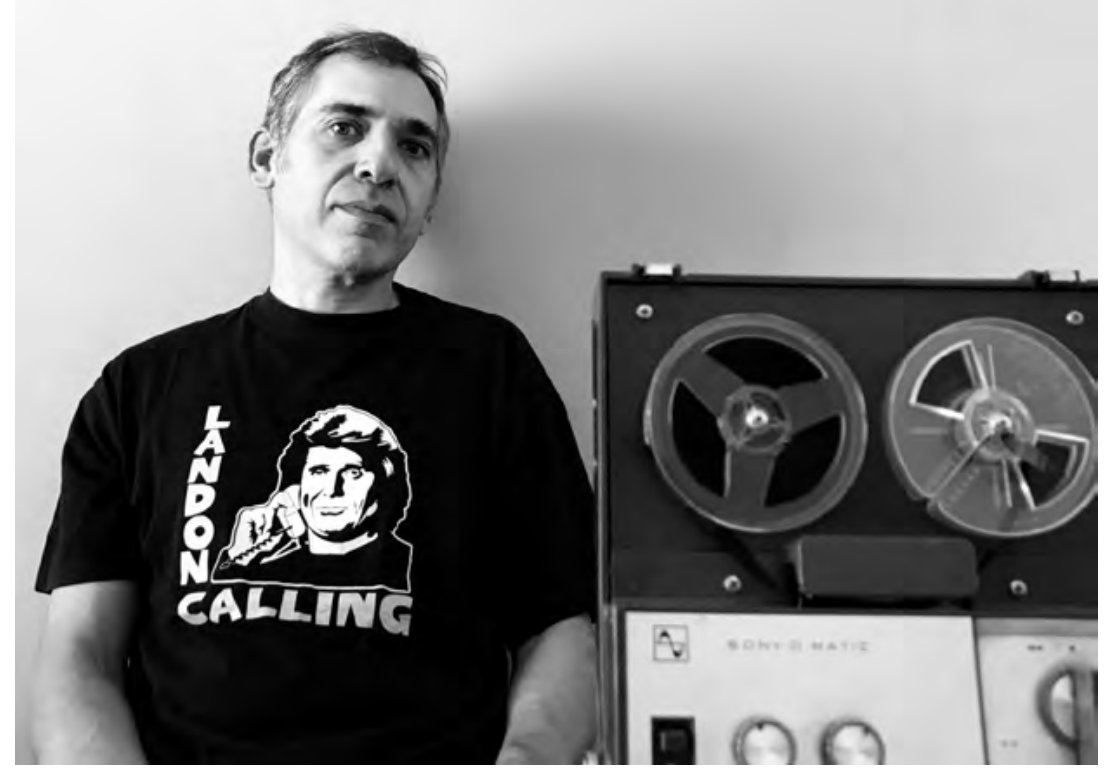

O jornalista argentino Daniel Flores. Foto: Carolina Reymúndez.

Daniel Flores é um especialista em subculturas do rock. Há anos o argentino, jornalista do La Nación e músico, dedica-se a reconstituir e a registrar a história das cenas roqueiras a partir do fim da década de 70 na Argentina. Nascido em 1973, nos anos 90 atuou como um dos fundadores das revistas de rock alternativas Esculpiendo Milagrose Revólver. Em 2009, publicou La manera correcta de gritar, uma história do ska na Argentina, e Pintó el punk!, livrinho com vinte capas de discos de punk para colorir, que incluía resenhas e comentários sobre as bandas. Foi organizador e um dos autores das coletâneas Gente que no: postpunks, darks y otros iconoclastas del under porteño en los 80, de 2010, e Derrumbando la Casa Rosada: mitos y leyendas de los primeros punks en la Argentina. 1978-1988, de 2011 todos publicados pela editora Piloto de Tormenta'. Em 2018, lançou seu último livro, Remeras de rock, pela editora Tren en Movimiento ${ }^{2}$. Trata-se de um apanhado eclético de críticas, ensaios, crônicas de viagem e entrevistas sobre o rock, camisetas de rock e outros fetiches roqueiros. Flores gentilmente nos concedeu a entrevista abaixo, na qual conversamos principalmente sobre o início do punk argentino, sua relação com a moda, a construção de sua identidade visual e de sua cultura material.

Além da música, uma das coisas mais impressionantes sobre o punk é o visual. Hoje, com a internet e a rapidez da informação midiática, é difícil dimensionar o real impacto que as imagens das primeiras bandas estrangeiras, como o Sex Pistols e os Ramones, tiveram na juventude latino-americana do fim dos anos 1970 e início dos 80. No capítulo "Arde Belgrano", de Derrumbando la Casa Rosada, o autor Alfredo Sainz menciona o consenso entre os primeiros punks porteños de que muitos tenham se 
tornado fãs das bandas antes mesmo de escutarem suas canções, ao verem suas fotos nas revistas de rock. Eu gostaria de começar nossa conversa pedindo que você falasse um pouco sobre esse início de uma cultura punk na Argentina, dessa repercussão do visual inglês e norte-americano e de como ele foi emulado.

Os inícios da cena punk, ou das cenas punks na Argentina se caracterizam, entre outras coisas, pela escassa informação. Os jovens que adotaram esta subcultura como própria, à sua maneira, o fizeram a partir de pequenas peças de um quebra-cabeça, que finalmente completavam como podiam, com seus próprios aportes. As fontes podiam ser breves artigos em revistas importadas ou "gravações de gravações de gravações" de discos ingleses ou norte-americanos, que chegavam ao seu destino ainda mais distorcidos que os originais. Outro fenômeno interessante é que, na Argentina, houve uma influência determinante do punk "feito" na Espanha, particularmente no País Basco, ou Euskadi. Quer dizer, a muitos meninos argentinos, o punk lhes chegava em uma versão já "traduzida", que eles, por sua vez, voltavam a interpretar a partir de sua própria cultura. Logo, 0 punk "à argentina" chegou assim a outros países, como Uruguai, Bolívia e Peru, onde outros jovens voltariam a reinterpretá-lo totalmente.

Na Introdução do livro, você comenta que as propositalmente escandalosas suásticas que os punks ingleses usavam talvez não fossem tão mal vistas na Argentina, pelo momento político que se vivia. Ou seja, a despeito das semelhanças entre o visual punk estrangeiro e o argentino, eu queria que você contasse um pouco sobre as discrepâncias. 0 que era particular à cena portenha, quais eram os objetos, os símbolos, as frases de efeito, as palavras de ordem específicas do contexto argentino?

Não são ideias "exclusivas", mas diria que o punk argentino, sobretudo o do início do movimento, teve um traço particularmente politizado. Há que se recordar que o punk começou a tomar algum impulso aqui precisamente no momento em que terminava uma ditadura militar e o pais acabava de perder uma guerra, pelas ilhas Malvinas. Também é interessante notar que o punk na Argentina (sempre nos concentrando em seu início, durante os anos 80) foi profundamente antirreligioso, anticatólico e antipapal, algo não muito presente nos Estados Unidos nem na Inglaterra, paises por si mesmos não tão religiosos, mas que foi, sim, muito visível no punk espanhol. Na Argentina, a Igreja Católica é o establishment e foi um alvo predileto dos punks. "Polícia" foi outra palavra muito presente naqueles inícios. A polícia era precisamente um dos maiores problemas dos jovens, talvez muito mais que hoje.

Quanto aos "objetos", algo interessante de assinalar é a "economia de recursos". Concretamente, o vestuário daqueles primeiros punks era uma versão mais austera e extremamente handmade. Não havia em Buenos Aires nenhuma loja como a de Malcolm McLaren... 
Você também tem um livro sobre o ska na Argentina, então vou aproveitar para pedir essa análise comparativa também em relação ao ska. Havia esse intercâmbio de referências com as bandas de fora? 0 visual era 0 mesmo ou passava por adaptações?

0 ska, certamente, chega um pouco mais tarde que o punk à Argentina, e de maneira ainda mais limitada. Neste caso, eu poderia repetir muitos dos termos já comentados sobre o punk: pouca informação, discos regravados até o infinito e muitos "vazios" preenchidos com o que se podia, com o que estava à mão. Claro que, se o punk foi uma cena marginal, o ska foi então ainda mais restrito; um gueto muito pequeno, quase familiar.

No decorrer dos capítulos de Derrumbando la Casa Rosada, é notável a presença feminina no punk argentino. Um deles, "La batalha del Riachuelo", foi escrito por Patricia Pietrafesa, figura bastante ativa do movimento e membro de diversas bandas punk. Você poderia falar um pouco sobre 0 que era ser garota na origem da cena?

É curioso. Pensar no lugar da mulher, inclusive em uma cena como o punk, hoje é irrisório. As mulheres tiveram uma participação muito limitada nesses anos, excetuando-se o papel de destaque, como você bem menciona, de alguém como Patricia Pietrafesa, música, editora de fanzine, [ $25^{\mathrm{O}}$ ] organizadora de festivais e grande agitadora, que sempre tentou "preencher" aqueles vazios de informação que eu mencionava, com conteúdo relevante. Houve outras mulheres, claro, como a banda feminina Exeroica ou algumas outras integrantes de grupos. Os testemunhos sempre coincidem em recordar o ambiente como muito machista e difícil para as meninas. A sociedade, neste sentido, tinha muito por avançar e o punk, ainda que detestasse reconhecê-lo, não escapava a essa problemática.

No punk inglês, em relação à moda, destacou-se a atuação de Vivienne Westwood, na época esposa de Malcolm McLaren e, se diz, responsável por vestir e produzir a imagem de várias bandas (inclusive dos Sex Pistols). Há algum personagem análogo no punk argentino, algum nome que tenha atuado junto às bandas ou que seja referência desse estilo?

Realmente não posso pensar em nenhum personagem análogo a Vivienne Westwood na Argentina. Creio recordar que existiu uma loja de estilo entre "gótico" ou "new romantic" chamada Kamasutra, por exemplo, mas definitivamente os punks de outrora não aprovavam esse tipo de consumo... No vestuário, o faça-você-mesmo era a norma. Inclusive se poderia falar, ainda melhor, de um "destrua-você-mesmo"! As calças e as camisetas com buracos e desbotados eram um furor.

Em 2013, o Costume Institute, do Metropolitan Museum de Nova York, organizou a exposição PUNK: Chaos to Couture, sobre a história e a influência do punk na moda e na cultura em geral. Na montagem, uma 
seção inteira era dedicada às camisetas mal costuradas e estampadas artesanalmente, exemplificando o DIY praticado por aqueles jovens. Sabe-se, no entanto, e isso fica claro em Derrumbando la Casa Rosada, que o punk valorizava o descartável, o desfeito, o efêmero. Parece, para você, um paradoxo que os artigos do punk tenham se tornado objetos de exposição em museu? Já houve alguma iniciativa assim em relação ao punk argentino?

É um paradoxo, sim. Mas um paradoxo esperado desse mundo em que tudo parece ter destino de "produto" ou de peça de museu. Não obstante, me parece importante destacar nesse ponto que nem todo o punk, nem na música, nem na estética, foi apropriado pelo "sistema". Para além de exposições como essa, há muita música (a maior parte, certamente) que segue representando um desafio ao mainstream.

Sobre ter havido já uma mostra assim na Argentina, não, não houve. Mas poderia te comentar que nosso livro Derrumbando la Casa Rosada foi lançado oficialmente no Museu do Livro e da Língua, parte da Biblioteca Nacional Argentina. Talvez esse seja um exemplo local do punk irrompendo em uma instituição cultural "oficial".

Você lançou recentemente um novo livro, chamado Remeras de rock. A camiseta de banda talvez seja uma das poucas unanimidades entre os fãs de rock, independente da vertente, pois ela é um "poderoso artefato comunicacional", como você define no livro, expressando individualidade e também pertencimento a um grupo. Mas essas motivações contrastam com o fenômeno mercadológico das camisetas de banda, que você também destaca no livro. A camiseta de banda - de qualquer banda - pode virar mero produto, consumido por quem nem a conhece e nunca ouviu suas músicas. Eu queria que você falasse um pouco sobre isso, sobre essa peça de roupa ao mesmo tempo tão simples e tão carregada de significados e de sua banalização pelo consumo de massa.

É um tema amplo e, como você bem disse, já o desenvolvo no livro. Algo que poderia adicionar aqui é uma particularidade dos começos do punk na Argentina (e que fique claro que, quando falo de Argentina, na verdade falo principalmente de Buenos Aires). Os punks dos anos 80 pintavam suas próprias camisetas. Faziam eles mesmos ou pediam a um amigo com habilidades plásticas, ou ainda podiam encomendar a uma loja especializada em "copiar à mão", sobre tela, fotos ou capas de discos - o que o cliente quisesse. Devido à falta de recursos, o "faça-você-mesmo" era realmente total. Não era uma escolha: não havia alternativa.

E é certo que nessa cena podia ocorrer o que hoje ocorre, por exemplo, com os Ramones em nível massivo: alguns se rendiam ao culto a determinadas bandas sem sequer as haver escutado. Um caso paradigmático é o do Dead Kennedys, cujo logotipo com as letras D e K era muito mais reproduzido do que a sua música, em Buenos Aires. Era um logo especialmente poderoso e fácil de copiar, e isso fez com que seu nome circulasse muito fortemente, muito mais que outros grupos. 
Para terminar: em Remeras de rock, você menciona o caso da clássica camiseta dos Ramones, com o logo da águia e os nomes dos integrantes ao redor, cujo percurso vai do antiestablishment em seu surgimento, passando para o stylist das celebridades e chegando nas grandes redes varejistas de vestuário. Talvez um novo capítulo dessa trajetória tenha surgido aqui no Brasil, nas últimas eleições presidenciais, em novembro, quando os eleitores do candidato de extrema-direita e admirador confesso de Donald Trump, Jair Bolsonaro, criaram versões da camiseta dos Ramones, por exemplo, com o brasão nacional e os nomes dos filhos do político. Como você vê esse tipo de ressignificação de um dos símbolos do punk e o que ele poderia indicar sobre a nossa relação com o punk na contemporaneidade? 0 punk ainda existe?

Incrivel isso de Bolsonaro-Ramones! Não conhecia o fenômeno. Na Argentina, Máximo Kirchner, filho da ex-presidenta Cristina Kirchner, está sendo investigado em distintos processos por suposta corrupção. Ele e sua família. Recentemente, Máximo apareceu em público com uma camiseta do disco do Metallica And Justice For All, apropriando-se da "mensagem" e do clássico disco da banda para sua própria causa.

Para além de Bolsonaro, desde já considero que o punk, sim, existe. Os Ramones são uma banda genial, da qual gosto muito, mas é certo que, [ $25^{2}$ ] de algum modo, foram uma cena em si mesmos. Me custa um pouco vê-los como "representantes" de algo mais amplo que eles mesmos e, em todo caso, as legiões de seus imitadores. Quando penso no punk, penso sobretudo em música "menos amável", por um lado, e também penso em uma operação independente, marginal, autogerida. Na verdade, me custa pensar nos Ramones como exemplo disso. Bolsonaro e seus seguidores pegaram o logo dos Ramones, mas não os imagino adaptando os logos de Doom ou utilizando para sua campanha uma canção de Poison Idea... 0 punk existe e é esse lugar que os Bolsonaros deste mundo nem sequer sabem onde fica. 